\title{
Comparative activities of milk components in reversing chronic colitis
}

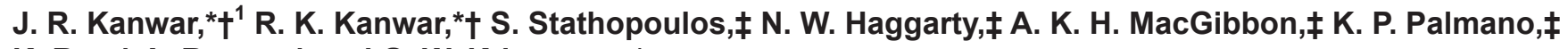 \\ K. Roy,† A. Rowan, $\ddagger$ and G. W. Krissansen* \\ *Department of Molecular Medicine and Pathology, Faculty of Medical and Health Sciences, University of Auckland, Auckland 1142, New Zealand \\ †Nanomedicine-Laboratory of Immunology and Molecular Biomedical Research (NLIMBR), Centre for Molecular and Medical Research (C-MMR), \\ School of Medicine (SoM), Faculty of Health, Deakin University, Waurn Ponds, Victoria 3217, Australia \\ łFonterra Research Centre, Palmerston North, New Zealand
}

\section{ABSTRACT}

Inflammatory bowel disease (IBD) is a poorly understood chronic immune disorder for which there is no medical cure. Milk and colostrum are rich sources of bioactives with immunomodulatory properties. Here we compared the therapeutic effects of oral delivery of bovine milk-derived iron-saturated lactoferrin (Fe$\mathrm{bLF})$, angiogenin, osteopontin (OPN), colostrum whey protein, Modulen IBD (Nestle Healthsciences, Rhodes, Australia), and cis-9,trans-11 conjugated linoleic acid (CLA)-enriched milk fat in a mouse model of dextran sulfate-induced colitis. The CLA-enriched milk fat significantly increased mouse body weights after $24 \mathrm{~d}$ of treatment, reduced epithelium damage, and downregulated the expression of proinflammatory cytokines and nitrous oxide. Modulen IBD most effectively decreased the clinical score at d 12, and Modulen IBD and OPN most effectively lowered the inflammatory score. Myeloperoxidase activity that denotes neutrophil infiltration was significantly lower in mice fed Modulen IBD, OPN, angiogenin, and Fe-bLF. A significant decrease in the numbers of $\mathrm{T}$ cells, natural killer cells, dendritic cells, and a significant decrease in cytokine expression were observed in mice fed the treatment diets compared with dextran sulfate administered mice. The Fe-bLF, CLA-enriched milk fat, and Modulen IBD inhibited intestinal angiogenesis. In summary, each of the milk components attenuated IBD in mice, but with differing effectiveness against specific disease parameters.

Key words: angiogenin, Osteopontin, conjugated linoleic acid, Modulen IBD, iron-saturated bovine lactoferrin (Fe-blf)

Received July 16, 2015.

Accepted November 16, 2015.

${ }^{1}$ Corresponding author: jagat.kanwar@deakin.edu.au

\section{INTRODUCTION}

Inflammatory bowel disease (IBD) is a chronic immune disorder affecting over 1.4 million people in the United States and 12 to 13/100,000 people worldwide (Podolsky, 1991). In healthy individuals, the intestine becomes inflamed in response to a pathogen then returns to a state of immunological tolerance once the pathogen is eradicated. However, in individuals with IBD, inflammation is not downregulated and the mucosal immune system remains chronically activated, leading to persistent intestinal inflammation (Kaser et al., 2010). Epidemiological and family studies demonstrate that genetic factors play a key role in susceptibility to IBD (Ek et al., 2014). Inflammatory bowel disease manifests as 2 clinical diseases, namely Crohn's disease and ulcerative colitis (UC; Podolsky, 1991; Kaser et al., 2010). Crohn's disease affects the entire wall of any region of the gastrointestinal tract, whereas the pathology associated with UC is confined to the mucosa of the colon and rectum. Even though UC and Crohn's disease are generally accepted as being clinically distinct conditions with distinguishing clinical, anatomical, and histological findings, no diagnostic procedure has been established to distinguish between them (Sands, 2004). Nearly $10 \%$ of patients suffering with IBD have indeterminate features between UC and Crohn's disease that cannot be clearly classified (Podolsky, 1991). Inflammatory bowel disease often predisposes to other diseases including arthritis, pyoderma gangrenosum, primary sclerosing cholangitis, and nonthyroidal illness syndrome (Liu et al., 2013). Neither Crohn's disease nor UC is medically curable; current treatment involves administration of high-dose steroids, immunomodulators, and surgery (Triantafillidis et al., 2011).

Milk and colostrum are rich sources of bioactives, including proteins, peptides, and lipids that play crucial roles in both neonates and adults, and represent potential health-enhancing nutraceuticals (Krissansen, 2007; Kanwar et al., 2009). Dairy bioactives have demonstrated bioavailability and anti-inflammatory and immunomodulatory properties capable of treating 
various human disorders (Krissansen, 2007; Kanwar et al., 2009). Orally administered bovine lactoferrin (LF) has been reported to reduce zymosan-induced ear-skin inflammation in mice (Hartog et al., 2007), adjuvantinduced arthritis in rats (Hayashida et al., 2004) and mice (Samarasinghe et al., 2014), and inflammation in other inflammatory disorders (Conneely, 2001); oral bovine milk-derived iron-saturated lactoferrin $(\mathbf{F e}-\mathbf{b L F})$ inhibits cancer in mice (Kanwar et al., 2008a, 2012). Lactoferrin promotes intestinal cell growth (Nemet and Simonovits, 1985), inhibits myelopoesis (Gentile and Broxmeyer, 1983), and has beneficial effects on iron (Ke et al., 2015) and lipid metabolism (Ono et al., 2013). It inhibits the formation of toxic reactive oxygen species by chelation and storage of plasma iron in the liver and spleen, which contributes to the amelioration of inflammatory states (Artym, 2009). For an average adult person, 1.4 to $3.4 \mathrm{~g}$ of lactoferrin can be administered per day without inducing any side effects (EFSA, 2012).

Angiogenin is a potent stimulator of the formation of new blood vessels (neoangiogenesis; Gao and $\mathrm{Xu}$, 2008). It promotes the migration, invasion, and proliferation of endothelial and smooth muscle cells, as well as the formation of tubular structures. It activates inositol-specific phospholipase $\mathrm{C}$, which promotes a transient increase in the intracellular levels of 1,2-diacylglycerol and inositol trisphosphate that facilitate angiogenesis (Bicknell and Vallee, 1988). Milk-derived angiogenin (also known as ribonuclease 5) induced myogenic differentiation and promoted muscle weight gain and grip strength when orally administered to mice (Knight et al., 2014).

Osteopontin (OPN) is a highly phosphorylated sialoprotein, which forms a prominent component of the mineralized extracellular matrices of bones and teeth (Butler, 1989). It plays a role in wound healing, immunological responses, tumorigenesis, bone resorption, calcification, obesity, and diabetes (Kahles et al., 2014). A short spliced from of OPN, termed OPN-c, upregulates several metabolic pathways to generate energy and acts as inhibitor of apoptosis (Shi et al., 2014). Osteopontin is a potent neuroprotectant that protects cortical neuron cultures against death induced by oxygen and glucose deprivation (Meller et al., 2005). It is regarded as a proinflammatory cytokine that facilitates the recruitment of monocytes or macrophages and stimulates cytokine secretion in leukocytes (Uede, 2011), it has also been associated with various inflammatory diseases (Uede, 2011); however, few studies have examined the effects of oral administration of OPN. Orally administered bovine OPN suppressed the growth of subcutaneous tumors in mice through a process involving inhibition of angiogenesis by blocking peptides that were absorbed into the circulation (Rittling et al., 2014). Bovine milk OPN dissolved in drinking water was orally administered to dextran sulfate (DSS)-treated mice in a model of IBD (da Silva et al., 2009). The treated mice experienced less weight loss, reduced colon shortening and disease activity, improved red blood cell counts, and reduced gut neutrophil activity.

The ingestion of colostrum is believed to play an essential role in gut growth and development in the neonate (Van Barneveld and Dunshea, 2011). Supplementing formula-fed piglets with a low-molecular weight fraction of bovine colostrum whey resulted in improved intestinal barrier function (De Vos et al., 2014). It has been reported that the colostrum whey proteins can be administered at $30 \mathrm{~g} / \mathrm{d}$ for 6 mo without inducing side effects in humans (Kennedy et al., 1995).

Conjugated linoleic acid consists of a series of positional and geometric dienoic isomers of linoleic acid that occur naturally in foods (Sébédio et al., 1999). It was reported that cis-9,trans-11 CLA, which is the major form of CLA in milk, improved weight gain and feed efficiency in rats (Chin et al., 1994). The ability of cis-9,trans-11 CLA to reduce the incidence and severity of atherosclerotic lesions is widely studied and hotly debated (Lee et al., 1994). It modified cardiovascular risk biomarkers in spontaneously hypertensive rats (Herrera-Meza et al., 2013). Dietary milk fat naturally enriched with cis-9,trans-11 CLA and vaccenic acids attenuated allergic dermatitis and airway disease in mice (Kanwar et al., 2008b). Oral cis-9,trans-11 CLA inhibited allergic sensitization and airway inflammation in mice via a peroxisome proliferator-activated receptor- $\gamma$ $(\mathrm{PPAR} \gamma)$-related mechanism (Jaudszus et al., 2008). The dose rate of CLA has been speculated to be $3.5 \mathrm{~g}$ for a 70-kg individual (MacDonald, 2000).

Modulen IBD (Nestle Healthsciences, Rhodes, Australia) is a powdered casein extract naturally enriched in the anti-inflammatory factor transforming growth factor (TGF)-32, intended for use as a sole source of nutrition in the active phase of Crohn's disease and for nutritional support during the remission phase (Fell et al., 2000). It has been shown to reduce inflammation in the gut and promotes gut mucosal healing (Fell, 2005), and was reported to significantly increase the BW of pediatric Crohn's disease patients (Buchanan et al., 2009). Modulen IBD is generally administered at 800 mg 3 times a day for a period of 6 mo (Triantafillidis et al., 2010).

Previous studies have acknowledged that consuming probiotics in milk and acidified milk can provide protection against weight loss and intestinal inflammation in a DSS-induced murine model of UC (Lee et al., 2015), Thus, in the present study, we sought to compare the 
effects of oral delivery of the immunomodulatory dairy components on different parameters of disease pathogenesis in a mouse model of chronic colitis.

\section{MATERIALS AND METHODS}

\section{Material}

The various milk components including Fe-bLF, angiogenin, OPN, colostrum whey protein (WP), and cis-9,trans-11 CLA-enriched milk fat were prepared in-house at the Fonterra Research Centre, Palmerston North, New Zealand. Preparation of Fe-bLF and cis9,trans-11 CLA-enriched milk fat has been described previously (Kanwar et al., 2008a,b). Modulen IBD was obtained from Nestle Australia.

Colostrum WP was prepared by adjusting the $\mathrm{pH}$ of fresh bovine skimmed colostrum to $\mathrm{pH} 6$, followed by dialysis overnight against milliQ water with several changes. The precipitated casein was removed by centrifugation $(3,000 \times g, 30 \mathrm{~min})$ and the remaining whey was dried by lyophilization.

Angiogenin was prepared by loading fresh bovine skim milk onto a column of Sepharose SP Big Beads (GE Healthcare Australia, Parramatta, Australia) to bind the basic milk protein fraction. Bound proteins were stepwise eluted with a $0.35 \mathrm{M} \mathrm{NaCl}$ solution, followed by a solution of $1.0 \mathrm{M} \mathrm{NaCl}$. The $1.0 \mathrm{M} \mathrm{NaCl}$ eluate was ultrafiltered using a cartridge with a cut-off of $30 \mathrm{kDa}$ (Millipore Prep/Scale TFF cartridge, Millipore, Billerica, MA). Permeate was diafiltered with MilliQ water (Millipore), using a UF cartridge with a cut-off of $3 \mathrm{kDa}$, to remove salt and then lyophilized.

Osteopontin was prepared from reconstituted acid whey protein concentrate (WPC80, Fonterra Co-operative Group, Palmerston North, New Zealand). Briefly, reconstituted whey protein concentrate (5\% TS) was adjusted to $\mathrm{pH} 4.6$ and loaded onto a Q Sepharose Big Beads column to bind the acidic whey protein fraction. Bound proteins were eluted stepwise with a solution of $0.25 \mathrm{M} \mathrm{NaCl}$ followed by a solution of $1.0 \mathrm{M} \mathrm{NaCl}$. The $1.0 \mathrm{M} \mathrm{NaCl}$ eluate was UF using a cartridge with a cut-off of $30 \mathrm{kDa}$ (Millipore Prep/Scale TFF cartridge). The retentate was diafiltered with MilliQ water (Millipore), using a UF cartridge with a cut-off of $3 \mathrm{kDa}$, to remove salt and then lyophilized.

\section{Diets}

The diets were prepared by Crop and Food Research (Palmerston North, New Zealand) using the Harlan Teklad AIN93G formulation as a base. Bovine casein and soybean oil in the control AIN93G diet were supplemented in the experimental diets with the dairy proteins and lipids, respectively, such that the protein and lipid contents of the diet were unchanged. The diets contained $1.25 \%$ (wt/vol) Fe-bLF, $0.3 \%$ angiogenin, $0.3 \%$ OPN, $1.25 \%$ (wt/vol) colostrum whey, $4.2 \%$ (wt/ vol) Modulen IBD, and 2\% (wt/vol) CLA-enriched milk fat.

\section{Induction of Colitis in BALB/c Mice}

The BALB/c male mice (7-12 wk old), weighing 21 to $23 \mathrm{~g}$ and maintained on an AIN93G diet, were administered $4 \%$ (wt/vol) DSS (and 10\% sucrose to aid nutrition) in their drinking water for 5 to $7 \mathrm{~d}$. Upon signs of rectal bleeding, $0.5 \mathrm{~mL}$ of normal saline was injected at 2 sites over the shoulders, to help avoid dehydration, and the mice were shifted to 1\% DSS in their drinking water for 3 to $4 \mathrm{~d}$ to study the progression from acute phase to chronic inflammation or recovery phase. After DSS administration, one set of colitic mice $(n=6)$ were fed with the AIN93G base diet to serve as a negative control, whereas another set of healthy mice were also fed on AIN93G base diet to serve as a positive control. Only mice that showed rectal bleeding were used in the treatment experiments. Groups of 6 mice were then fed an AIN93G diet supplemented with one of the milk components for 14 to $18 \mathrm{~d}$ until d 24. The DSS administered to mice fed the treatment diets were scored for decreased BW, inflammation, and epithelial damage. The mice were euthanized in accordance with the ethics guidelines as per the approved protocol by The University of Auckland, Faculty of Medical and Health Sciences (AEC/06/2003/R138). The anesthesia was induced by 1.5 to $2 \%$ isofluorane administration and humanely killed by a slowly filled $\mathrm{CO}_{2}$ chamber while under anesthesia. Terminal bleeding was performed by cardiac puncture and the organs were isolated, weighed independently, and examined for enlargement and inflammation. The intestines were fixed in $10 \%$ formalin to be examined histopathologically.

\section{Histology}

Cryostat $8-\mu \mathrm{m}$ sections of the intestines were placed on slides, air-dried, and fixed for $10 \mathrm{~min}$ in ice-cold acetone. The sections were stained with hematoxylin and eosin to assess the degree of inflammation.

\section{Myeloperoxidase Activity}

Myeloperoxidase (MPO) activity is widely accepted as a marker of neutrophil infiltration into tissues and has also been commonly correlated with white cell 
Table 1. Assessment of inflammation symptoms and inflammatory score ${ }^{1}$

\begin{tabular}{llll}
\hline Score & Diarrhea score & Visible fecal blood & Inflammatory score \\
\hline 0 & Normal pellets & None & No inflammation \\
1 & Slightly loose feces & None & Start of inflammation \\
2 & Loose feces & Slightly bloody & Slight inflammation \\
3 & Watery diarrhea & Bloody & Moderate inflammation or edema \\
4 & Watery diarrhea & Blood in whole colon & Heavy inflammation or edema \\
\hline
\end{tabular}

${ }^{1}$ The overall score reflects the degree of diarrhea, visible fecal blood, and the inflammatory score on the day of termination. The inflammatory score reflects macroscopic appearance of the colon judged by degree of inflammation and presence of ulcerations or edema.

counts and lesions in DSS-treated rats. Colon sections were assayed for MPO activity as described Krawisz et al. (1984).

\section{Assessment of Inflammation Symptoms and Inflammatory Score}

Clinical assessment of inflammation included daily monitoring of BW and general condition of health, including the presence of diarrhea and fecal blood. Sections of the intestines were graded in a range from 0 to 4 as to the degree and depth of inflammation, crypt damage, and regeneration (Table 1).

\section{Detection and Identification of Immune Cells}

Fluorescein isothiocyanate-conjugated rat anti-mouse cluster of differentiation (CD) 4 monocloncal antibody (mAb), rat anti-mouse CD8 $\alpha$ antibody, anti-mouse natural killer (NK) 1 antibody (BioLegend, San Diego, CA), and anti-mouse dendritic cell marker 33D1 antibody (eBioscience, San Diego, CA) were used to determine the respective expression of these markers in the tissue slides. Cells from 5 different images that were positive for $\mathrm{CD} 4+, \mathrm{CD} 8+, \mathrm{NK}+$, and dendritic cell $(\mathbf{D C}+)$ expression were counted, and plotted in a graph.

\section{Analysis of Cytokine Expression}

Cytokine expression in whole colonic tissue homogenates was analyzed. Dissected tissues were homogenized in radio-immunoassay precipitation buffer, the homogenates centrifuged for $10 \mathrm{~min}$ at $25,000 \times g$ and $4^{\circ} \mathrm{C}$, and the supernatants frozen in aliquots at $-80^{\circ} \mathrm{C}$. The concentrations of IL-4, IL-6, IL-10, IL-18, IFN- $\gamma$, tumor necrosis factor (TNF)- $\alpha$, granulocytemacrophage colony-stimulating factor (GM-CSF), and nitric oxide were analyzed by ELISA according to the manufacturer's instructions (R\&D Systems, Minneapolis, MN), and expressed as picograms per $100 \mathrm{mg}$ of colonic tissue.

\section{Measurement of Blood Vessel Density}

Blood vessels in sections prepared from the small intestine of mice were stained with anti-CD31 and anti-CD105 mAb, or perfused with 3,3'-diheptyloxacarbocyanine iodide (DiOC7), and counted in blindly chosen random fields to record mean vessel density per surface area.

\section{Assessment of Apoptosis of T cells in Intestinal Sections}

Sections prepared from the small intestine were blocked with $3 \%$ BSA for $1 \mathrm{~h}$ and washed thrice in water. They were stained by the terminal deoxynucleotidyl transferase dUTP nick end labeling (TUNEL) method using the in situ cell death detection kit from Roche (Basel, Switzerland). They were then doublestained for $1 \mathrm{~h}$ with a mouse anti-CD3 antibody (Santa Cruz Biotechnology, Dallas, TX), followed by staining with a tetramethylrhodamine-conjugated secondary antibody (Sigma-Aldrich, St. Louis, MO) for $1 \mathrm{~h}$. Slides were mounted and viewed by fluorescence microscopy. Cells from 5 different images that were positive for both CD3 and the TUNEL stain were counted and plotted to represent the apoptosis index.

\section{Statistical Analysis}

All data are expressed as mean \pm standard deviation. The statistical significance of the differences was evaluated using the Student's t-test. Statistical significance was defined as $P<0.05$ and $P \leq 0.01$.

\section{RESULTS}

\section{DSS-Induced Induction of Colitis in BALB/c Mice}

Oral administration of $4 \%$ (wt/vol) DSS in the drinking water led to induction of acute intestinal inflammation as observed by rectal bleeding. The mice were immediately shifted to $1 \%$ DSS for 3 to $4 \mathrm{~d}$ to 
(a)

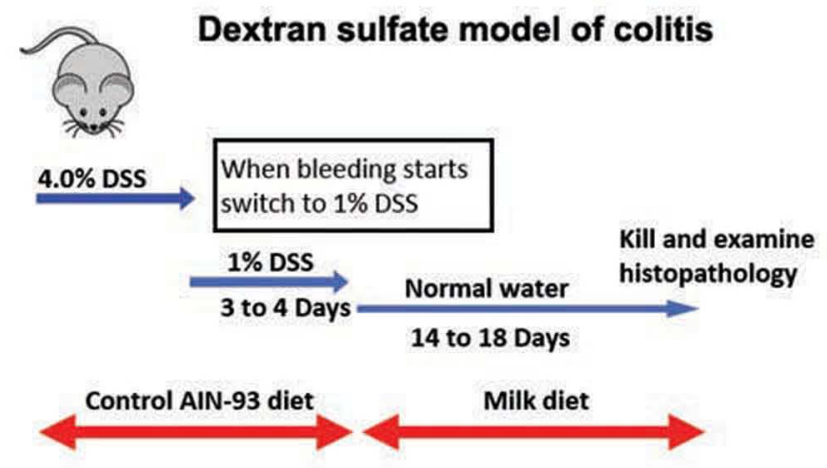

(c)

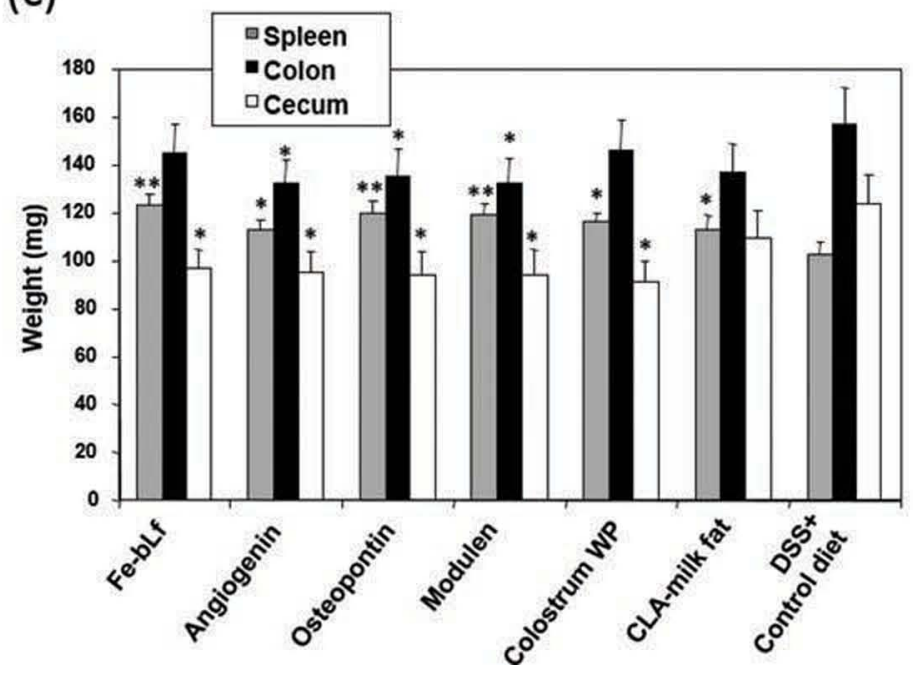

(b)

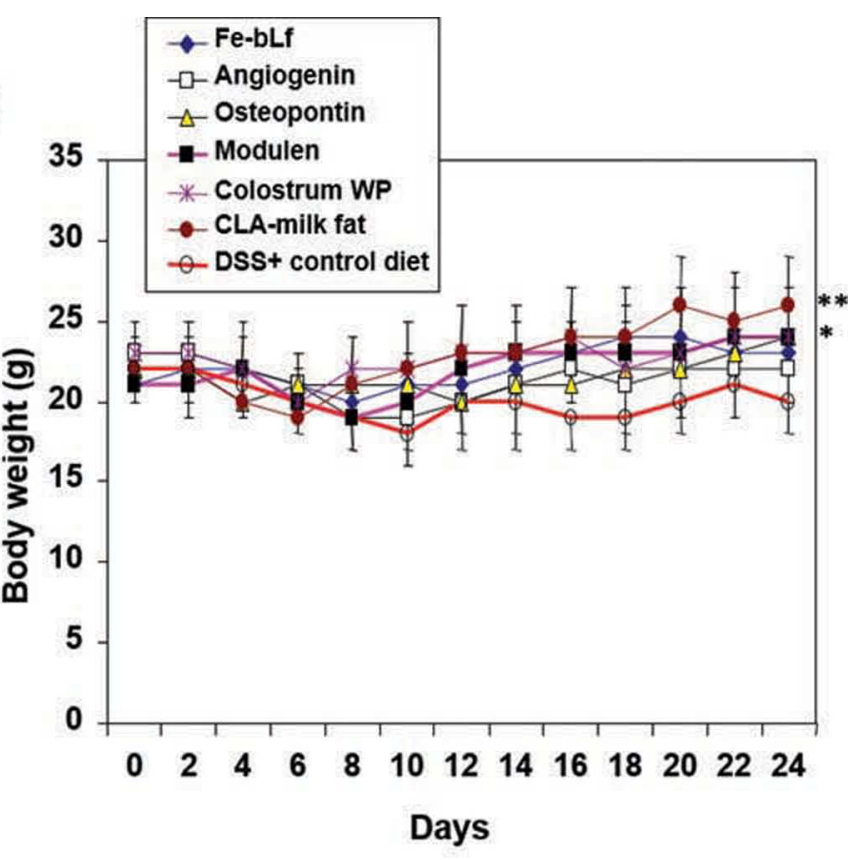

Figure 1. Overview of induction of dextran sulfate (DSS)-induced colitis in BALB/c mice. (a) Mice received $4 \%$ DSS in their drinking water for 5 to $7 \mathrm{~d}$, and once rectal bleeding was observed they were shifted to $1 \%$ DSS for 3 to $4 \mathrm{~d}$. They were then returned to normal drinking water, at which time they were randomized to receive the base AIN93G diet (Crop and Food Research, Palmerston North, New Zealand), or the same diet supplemented with 1 of the 7 different milk components for 14 to $18 \mathrm{~d}$. Tissues and organs were then collected and examined. (b) Daily change in BW of groups of mice; each group consisted of 5 to 6 mice. (c) Spleen, colon, and cecum weights (mg) at the end of the study. Data values are expressed as means \pm SD. Differences compared with the DSS + control diet were considered significant when $* P<0.05$, and highly significant when ${ }^{* *} P<0.01$. Fe-bLF $=$ bovine milk-derived iron-saturated lactoferrin; WP $=$ whey protein. Color version available online.

Table 2. Pathophysiological parameters (means $\pm \mathrm{SD}$ ) in mice with chronic inflammatory bowel disease

\begin{tabular}{lcccccrr}
\hline Item $^{1}$ & Fe-bLf $^{2}$ & Angiogenin & Osteopontin & \multirow{2}{*}{ Modulen $^{3}$} & Colostrum WP $^{5}$ & CLA-milk fat $^{\text {DSS }}{ }^{6}+$ control diet \\
\hline BW at d 0 & $21.2 \pm 1.5$ & $24 \pm 3$ & $22 \pm 2$ & $21.2 \pm 3$ & $23.4 \pm 2$ & $22 \pm 2$ \\
BW at d 24 & $22.75 \pm 3$ & $22.5 \pm 2$ & $23.6 \pm 2.3$ & $23.5 \pm 3.5$ & $24.5 \pm 2.5$ & $25 \pm 2.5$ & $22 \pm 2$ \\
Colon length & $8.6 \pm 2.5$ & $8 \pm 1$ & $8.6 \pm 2.5$ & $10 \pm 2$ & $9 \pm 0.8$ & $9 \pm 0.7$ & $7.5 \pm 1$ \\
Water intake & $38.3 \pm 4.5$ & $46 \pm 4.5$ & $45 \pm 5$ & $48 \pm 3.5$ & $38.3 \pm 4$ & $36 \pm 2.5$ & $35 \pm 3.5$ \\
Crypt area & $42 \pm 5$ & $38.6 \pm 5$ & $42 \pm 5.5$ & $34.5 \pm 3.8$ & $34.5 \pm 4.5$ & $33.5 \pm 3.5$ & $22.5 \pm 3.5$ \\
\hline
\end{tabular}

${ }^{1}$ Body weight in grams; colon length at d 24 in cm; water intake over 2 wk in milliliters; crypt area refers to percentage of total mucosal area. ${ }^{2} \mathrm{Fe}-\mathrm{bLf}=$ bovine milk-derived iron-saturated lactoferrin.

${ }^{3}$ Modulen IBD, Nestle Healthsciences, Rhodes, Australia.

${ }^{4} \mathrm{WP}=$ whey protein.

${ }^{5} \mathrm{DSS}=$ dextran sulfate. 
induce sustained chronic inflammation (Figure 1a). The mice failed to thrive, as demonstrated by plateauing of their BW. In contrast, mice on each of the 6 supplemented diets showed increased BW compared with DSS-administered, diseased mice that were fed the control base diet. Mice fed OPN, Modulen IBD (all $P<0.05)$, and CLA-enriched milk fat $(P \leq 0.01)$ showed a significant increase in average BW at the end of $24 \mathrm{~d}$ (Figure 1b). Colon length was increased by 1.15 fold by Fe-bLF and OPN, 1.2 fold by colostrum WP and CLA-enriched milk fat, and 1.33 fold by Modulen IBD. Intestinal crypt area was increased 1.87 fold by Fe-bLF and OPN, 1.71 fold by angiogenin, 1.53-fold by colostrum WP, and by 1.48 fold CLA-enriched milk fat (Table 2). The Fe-bLF, OPN, Modulen IBD (all $P$ $\leq 0.01$ ), angiogenin, colostrum WP, and CLA-enriched milk fat (all $P<0.05$ ) significantly increased spleen weight. Angiogenin, OPN, and Modulen IBD significantly decreased $(P<0.05)$ colon weight compared with the DSS-administered mice fed the control base diet. The cecum weight was significantly reduced $(P<$ 0.05) in mice fed Fe-bLF, angiogenin, OPN, Modulen IBD, and colostrum WP (Figure 1c).

\section{Clinical and Histological Data}

Administration of DSS led to the induction of acute inflammation in mice. The MPO activity, which is used as a quantitative assessment of neutrophil infiltration, was nonsignificantly reduced in the colon sections of mice fed colostrum WP $(8 \pm 3 \mathrm{U} / \mathrm{mg}$ of protein $)$ and CLA-enriched milk fat $(7 \pm 2 \mathrm{U} / \mathrm{mg}$ of protein), and significantly $(P<0.05)$ reduced in mice fed Fe-bLF $(5 \pm 2 \mathrm{U} / \mathrm{mg}$ of protein), angiogenin $(6 \pm 2 \mathrm{U} / \mathrm{mg}$ of protein), OPN ( $6 \pm 2 \mathrm{U} / \mathrm{mg}$ of protein), and Modulen IBD $(5 \pm 2 \mathrm{U} / \mathrm{mg}$ of protein), compared with mice administered with DSS fed the control base diet ( $9 \pm 3$ $\mathrm{U} / \mathrm{mg}$ of protein; Figure 2a).

Mice were clinically assessed daily and given a score for their general condition of health, including BW (Figure 2b). The clinical score gradually increased to 3 upon DSS administration, plateaued, and then, after removal of DSS and feeding colitic mice the control base diet, slowly declined to a score of 1 at d 24. Modulen IBD caused a rapid and significant $(P \leq 0.01)$ decrease in the clinical score, such that Modulen IBD-fed mice had a clinical score of 1 at $d 12$ and 0 at d 16. The CLAenriched milk fat also caused a rapid and significant $(P$ $\leq 0.01)$ decrease in the clinical score, which reached 0 on d 16. Both Fe-bLF and OPN significantly $(P<0.05)$ reduced the clinical score from 3 to 1 on $\mathrm{d} 14$ and from 1 to 0 on d 20. Colostrum WP reduced the clinical score to 1 on d 20 and 0 on d 22, whereas angiogenin reduced the clinical score to 1 on d 22 and 0 on d 24 .
Sections of the colon were stained with hematoxylin and eosin and graded with respect to the amount of inflammation and epithelium damage. The Fe-bLF, angiogenin, colostrum WP, OPN, Modulen IBD, and CLA-enriched milk fat reduced the inflammatory score from $2 \pm 1$ at $\mathrm{d} 24$ to $1 \pm 0.5(P<0.05), 1.5 \pm 0.5,1.5$ \pm 0.5 (both $P>0.05), 0.5 \pm 0.5,0.5 \pm 0.5$ (both $P \leq$ $0.01)$, and $1 \pm 0.5(P<0.05)$, respectively, at the end of the study, after humanely killing the mice after 24 d of treatment. They reduced the epithelium damage score from $2 \pm 0.5$ at $\mathrm{d} 24$ to $1 \pm 0.5,1 \pm 0.5,1 \pm 0.5$, $1 \pm 0.5,1 \pm 0.5$ (all $P<0.05)$, and $0.5 \pm 0.5(P \leq$ 0.01 ), respectively, at the end of the study (Figure $2 \mathrm{c}$ ).

The colonic mucosa and submucosa of DSS-induced colitic mice fed the control base diet were infiltrated with increased numbers of immune cells compared with undiseased, healthy mice fed the same diet. A significant increase was observed in the numbers of infiltrated CD4+ and NK [asialo GM1 (a type of glycosphingolipid expressed on NK cells)-positive] cells (both $P \leq 0.001$ ), as well as CD8+ cells and DC (both $P \leq 0.01)$ compared with untreated mice (Figure $2 \mathrm{~d}$ ). Osteopontin $(P$ $\leq 0.01$ ), Fe-bLF, angiogenin, and Modulen IBD (all $P$ $<0.05$ ) significantly reduced infiltration of CD4+ cells. In contrast, colostrum WP and CLA-enriched milk fat had no significant effect on infiltration by CD4+ cells. Angiogenin, OPN, colostrum WP, and CLA-enriched milk fat (all $P \leq 0.01$ ), as well as Fe-bLF $(P \leq 0.05)$, significantly decreased $\mathrm{CD} 8+$ cell infiltration. The numbers of infiltrated $\mathrm{NK}+$ cells were significantly reduced in Fe-bLF, angiogenin, OPN (all $P \leq 0.01$ ), Modulen IBD, and colostrum WP-fed mice $(P \leq 0.05)$, whereas the CLA-enriched milk fat diet had no significant effect. Angiogenin $(P<0.05)$ and OPN $(P<0.01)$ were the only milk components to significantly decrease the number of DC, whereas CLA-enriched milk fat increased DC numbers, albeit nonsigificantly (Figure 2d).

\section{Effects of Milk Components on Cytokine Expression}

Colitic mice had elevated levels of colonic cytokine expression compared with healthy mice provided normal water. The OPN $(P \leq 0.001)$, angiogenin, and CLA-enriched milk fat (both $P \leq 0.01$ ), as well as FebLF, Modulen IBD, and colostrum WP (all $P<0.05$ ), significantly reduced the levels of IL-6. Angiogenin, OPN, and CLA-enriched milk fat (all $P \leq 0.01$ ) and Fe-bLF, Modulen IBD, and colostrum WP diet (all $P<$ $0.05)$ significantly reduced IL-10 expression. Colostrum $\mathrm{WP}$ and CLA-enriched milk fat (both $P \leq 0.01$ ) and Fe-bLf, angiogenin, OPN, and Modulen IBD (all $P<$ 0.05 ) significantly reduced IL-18 expression (Figure 3a).

Each of the milk components also significantly inhibited the DSS-induced expression of IFN- $\gamma$, TNF- $\alpha$, IL-4, 
(a)
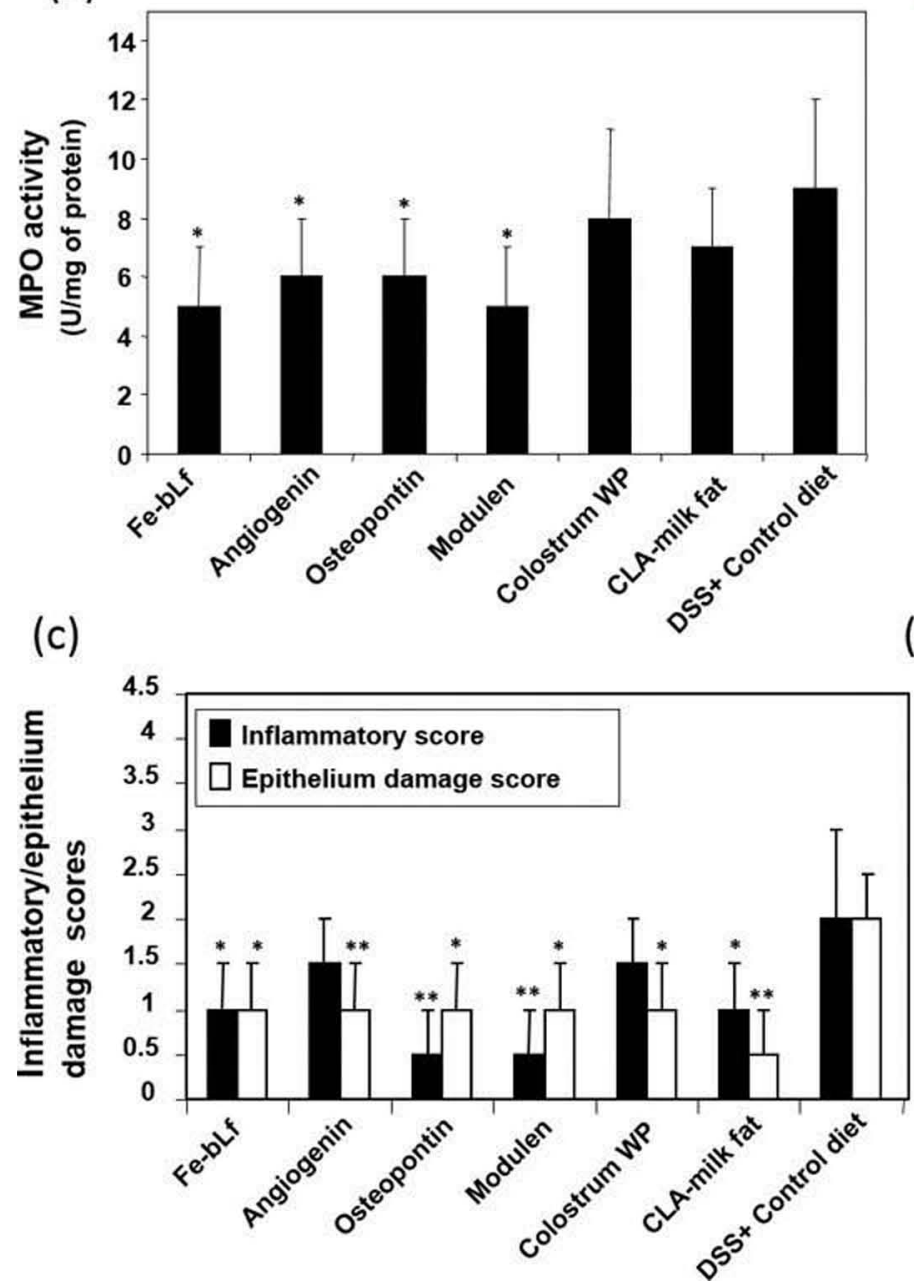

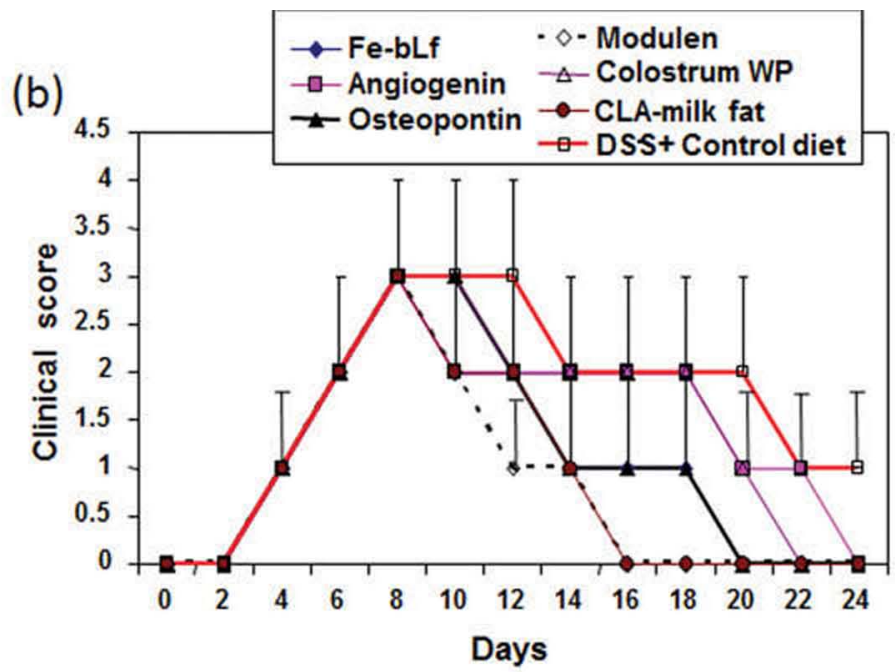

(d)

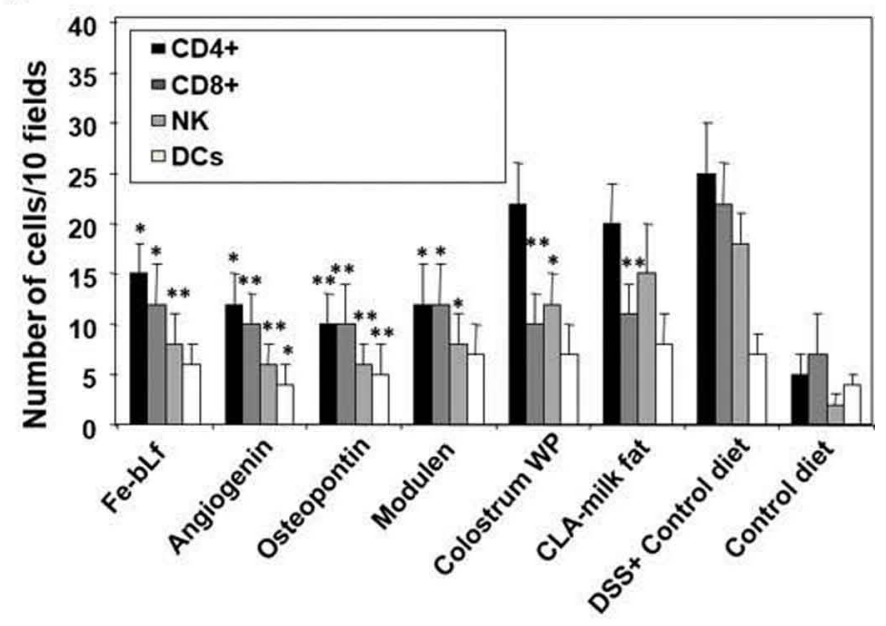

Figure 2. Therapeutic effects of oral feeding of milk components on dextran sulfate (DSS)-induced colitis. (a) Myeloperoxidase (MPO) activity (U/mg of protein) in sections of the colon, (b) clinical score, (c) inflammation and epithelium damage scores, and (d) numbers of immune cells that have infiltrated the lamina propria of the small intestine after oral feeding of different milk components to mice. The data are expressed as the means $\pm \mathrm{SD}$; different compared with the DSS + control diet: ${ }^{*} P<0.05,{ }^{*} P<0.01$. Fe-bLF $=$ bovine milk-derived iron-saturated lactoferrin; WP = whey protein; $\mathrm{CD}=$ cluster of differentiation; $\mathrm{NK}=$ natural killer; $\mathrm{DCs}=$ dendritic cells. Color version available online.

IL-5, GM-CSF, and NO (Figure 3(b)). Angiogenin was particularly effective $(P \leq 0.01)$ at inhibiting IFN- $\gamma$ expression compared with all other groups $(P<0.05)$. Angiogenin, OPN, and CLA-enriched milk fat (all $P \leq$ 0.01) were more effective than Fe-bLF, Modulen IBD, and colostrum WP (all $P<0.05$ ) at reducing TNF- $\alpha$ expression. The CLA-enriched milk fat was comparatively more effective $(P \leq 0.01)$ in inhibiting IL-4 and IL-5 expression compared with all other groups (all $P<$ 0.05). The Fe-bLF, colostrum WP, and CLA-enriched milk fat were more effective (all $P \leq 0.01$ ) at reducing GM-CSF expression than were angiogenin, OPN, and Modulen IBD (all $P<0.05$ ). The milk components were equally effective in downregulating NO expression (all $P<0.05$ ).

\section{Effects of Milk Components on Angiogenesis}

Antibody staining of CD31 and CD105 was performed to detect the presence of endothelia in sections prepared from the small intestine, where CD105 marks newly formed blood vessels (neovascularization). The DiOC7 staining was done to demarcate perfusable vasculature. Conjugated linoleic acid-enriched milk fat and Fe-bLF significantly $(P<0.05)$ reduced both CD31 and DiOC7 staining. Modulen IBD significantly $(P<0.05)$ reduced 
CD105 and DiOC7 staining, whereas OPN significantly reduced $(P<0.05)$ CD105 expression. In contrast, angiogenin and colostrum WP had no significant effect on the angiogenesis markers (Figure $3(\mathrm{c})$ ).

\section{Effects of Milk Components on Apoptosis of T cells}

The apoptotic index for small intestinal $\mathrm{T}$ cells was obtained by double-staining $\mathrm{T}$ cells with the TUNEL agent and an anti-CD3 monoclonal antibody. Both FebLF and Modulen IBD highly significantly $(P \leq 0.01)$ induced the apoptosis of T cells, whereas all the other dairy components significantly $(P<0.05)$ induced apoptosis..

\section{DISCUSSION}

As reported previously (Okayasu et al., 1990), oral delivery of DSS induced rectal bleeding and diarrhea, which are common symptoms of colitis. Blood was found in the whole colon associated with inflammation, enlarged spleens, and weight loss. Histological features that typify colitis, including shortening of the colon, decreased crypt density (increased spacing between crypts), and severe infiltration of inflammatory cells to the intestinal wall, were evident.

It is also established in the current study (Figure 1b), that DSS treatment leads to anorexia in rats. As IBD is known to manifest itself anywhere along the (a)

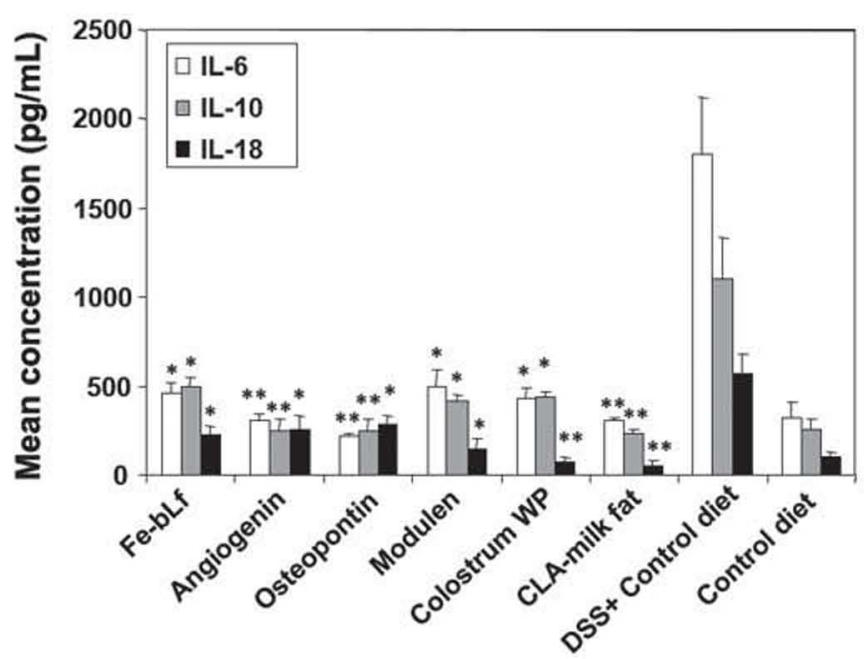

(c)

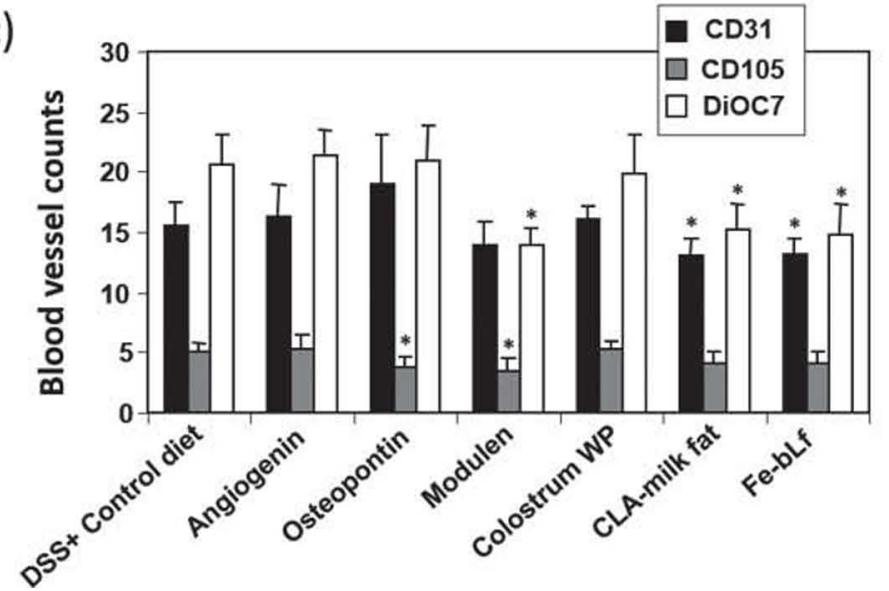

(b)

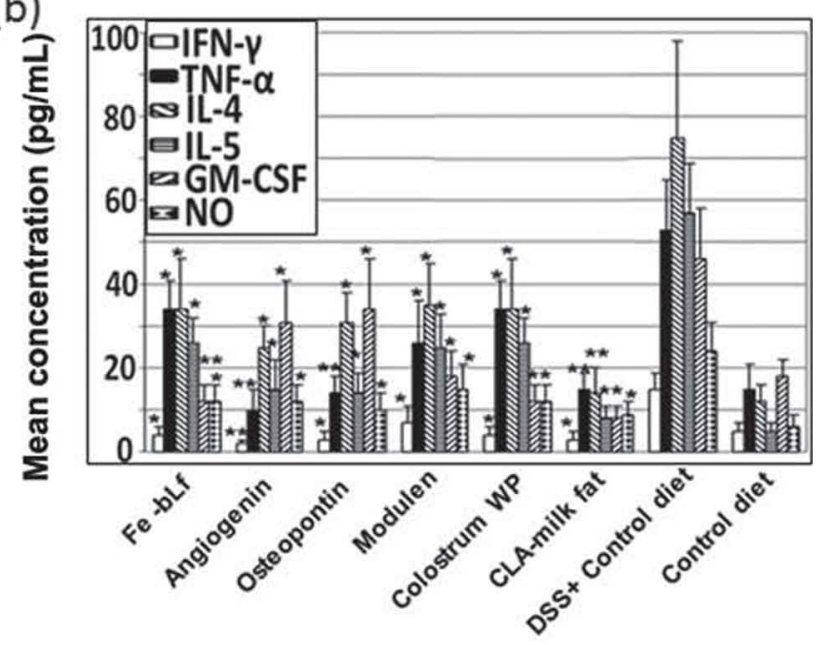

(d)

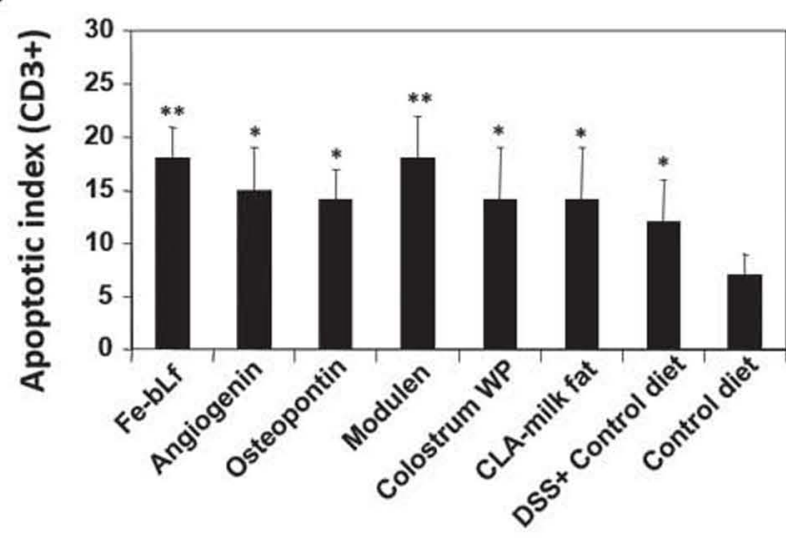

Figure 3. Anti-inflammatory and antiangiogenic activity of milk components. (a,b) Effect of oral feeding of different milk components on cytokine expression in colon homogenates. (c) Blood vessels in sections of the small intestine were stained with anti-CD31 and anti-CD105 monoclonal antibody $(\mathrm{mAb})$, or perfused with 3,3'-diheptyloxacarbocyanine iodide (DiOC7), and counted in blindly chosen random fields to record mean vessel density per surface area $\left(0.155 \mathrm{~mm}^{2}\right)$. (d) Apoptosis of $\mathrm{T}$ cells in the lamina propria region of the small intestine. Sections were double-stained with the fluorescein isothiocyanate-labeled terminal deoxynucleotidyl transferase dUTP nick end labeling agent and with an anti-CD3 $\mathrm{mAb}$. Data represent mean values $\pm \mathrm{SD}$; different compared with the DSS + control diet: ${ }^{*} P<0.05$, and ${ }^{* *} P<0.01$. Fe-bLF $=$ bovine milk-derived iron-saturated lactoferrin; $\mathrm{WP}=$ whey protein; GM-CSF $=$ granulocyte-macrophage colony-stimulating factor; NO = nitric oxide; $\mathrm{CD}=$ cluster of differentiation. 
dietary tract, from mouth to anus, diseased patients are likely to experience regular pain from food ingestion or malabsorption; hence, IBD may lead to anorexia and associated weight loss. In the present study, CLAenriched milk fat, OPN, and Modulen IBD led to BW gain in mice. In accord with the results from da Silva et al. (2009), OPN proved to be one of the most effective agents at combating colitis, causing significant increases in BW, colon length, and crypt area. da Silva et al. (2009) also reported that OPN-treated mice experienced less disease activity, improved red blood cell counts, and reduced gut neutrophil activity. Modulen IBD has been reported to significantly increase BW in $80 \%$ of patients out of 110 patients (Buchanan et al., 2009). It has also been reported that CLA milk fat leads to gain in BW by increasing the muscle mass of the body (Sagwal and Kansal, 2010); thus, our findings were in accordance with published reports.

Modulen IBD, which is an enteral nutrition used in the treatment of IBD (Mayberry, 2004), proved to be the most effective treatment in reducing the clinical score in mice with chronic IBD, followed by CLA-enriched milk fat, OPN, and Fe-bLF, and then angiogenin and colostrum WP. These results were not unexpected, as Modulen IBD is enriched in the potent immunosuppressor TGF- $\beta$, whereas cis-9,trans-11 CLA exerts anti-inflammatory effects, as evidenced by its ability to inhibit LPS-induced activation of macrophages (Dowl-

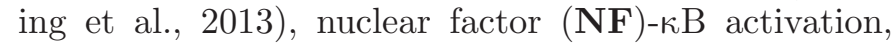
and IL-12 production by dendritic cells (Loscher et al., 2005) and subsequent Th17 responses (Draper et al., 2014). Intake of butter naturally enriched with cis-9,trans-11 CLA reduced systemic inflammatory mediators in healthy young adults (Penedo et al., 2013); likewise, diets enriched with either cis-9,trans-11 CLA or bovine milk fat enriched in cis-9,trans-11 CLA and its precursor, vaccenic acid, attenuated allergic airway disease in mice (Kanwar et al., 2008b). Treatment with cis-9,trans-11 CLA inhibited allergic dermatitis in mice (Sun et al., 2011). Conjugated linoleic acid milk fat treatment also worked better than osteopontin and FebLF, followed by angiogenin and colostrum WP. This is because CLA milk fat is considered a natural inflammation fighter as it has the ability to reduce the TNF- $\alpha$ and IL-6 expression (O'Shea et al., 2004). It has been reported that CLA induced a reduction in expression of COX2, TNF- $\alpha$, NO, and IL-1 $\beta$ by downregulating peroxisome proliferator-activated receptor- $\gamma$ (Changhua et al., 2005).

Analysis of the inflammatory and epithelial damage scores revealed that mice fed diets containing OPN and Modulen IBD showed the most significant reduction in inflammatory score, whereas mice fed the CLA-enriched milk fat diet showed the most significant reduction in the epithelium damage score. In a prospective, 10-wk open-label trial, children with active, naive Crohn's disease were randomized to receive Modulen IBD or oral corticosteroids (Borrelli et al., 2006). The proportion of children that showed mucosa healing was significantly higher in those children treated with Modulen IBD than those treated with corticosteroids. Cell-mediated immunity against the luminal flora is reported to be the key event in driving the inflammatory process that leads to intestinal lesions in IBD (Podolsky, 1991; Kaser et al., 2010).

The Fe-bLF, angiogenin, OPN, and Modulen IBD significantly lowered neutrophil infiltration, as evidenced by reduced MPO activity. Human LF has been reported to protect against LPS-induced acute lung injury in mice, in part by preventing neutrophil infiltration (Li et al., 2012). Studies have also claimed that angiogenesis-promoting cytokine angiogenin promotes inflammation by increasing the vascular angiogenesis in patients with IBD (Koutroubakis et al., 2004). However, in the present study, we found that oral-fed angiogenin in mice with chronic IBD led to a decrease in the neutrophil infiltration. Paradoxically, OPN is known to increase neutrophil and macrophage infiltration via its RGD sequence ( $\mathrm{Li}$ et al., 2012). Thus, injection of OPN into mice led to a robust increase in peritoneal infiltration of neutrophils (Atai et al., 2011). Further, OPN is important for the functioning of fibroblasts, macrophages, and lymphocytes during inflammation (Koh et al., 2007). In the present study, oral feeding of OPN paradoxically lowered neutrophil infiltration into the intestine. In support, DSS-induced acute colitis is exacerbated in OPN-null mice, associated with downregulation of TNF- $\alpha$ expression and nonprogrammed cell death, suggesting that OPN is required for mucosal protection in acute inflammatory colitis (Da Silva et al., 2006).

Significant decreases in the infiltration of $\mathrm{T}$ cells, NK cells, and dendritic cells were observed in mice fed the dairy component-supplemented diets when compared with the DSS-administered mice fed the control base diet (Figure 4). Clinical evidence obtained from previously published reports (Sartor, 1995) suggests that uncontrolled $\mathrm{T}$ lymphocyte activation is a central pathogenic mechanism of chronic intestinal inflammation. Cell-mediated immunity against the luminal flora is reported to be the key event in driving the inflammatory process that leads to intestinal lesions in inflammatory bowel disease (ten Hove et al., 2002). The proportions of circulating $\mathrm{CD} 4(+)$ and $\mathrm{CD} 8(+)$ $\mathrm{T}$ lymphocytes is generally elevated in patients with IBD (Funderburg et al., 2013). Thus, immunodeficient mice have been commonly used to investigate the immunological mechanisms involved in the induction of 


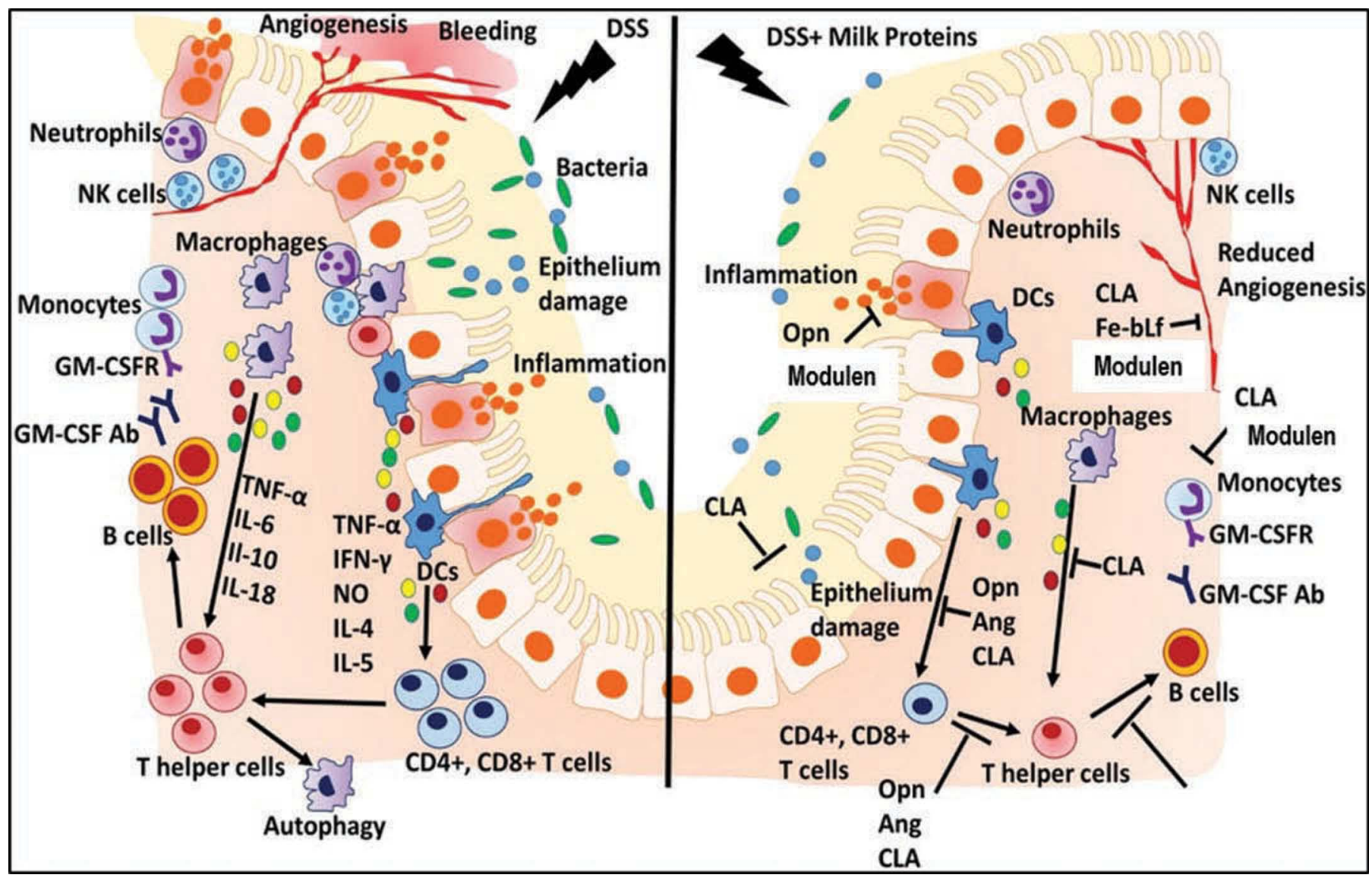

Figure 4. Anti-inflammatory and immunomodulatory potential of milk-derived components. Dextran sulfate (DSS)-induced colitis in $\mathrm{BALB} / \mathrm{c}$ mice led to chronic inflammation, associated with damage to the intestinal epithelium, intestinal bleeding, and diarrhea. The numbers of cluster of differentiation (CD) $4^{+}$and $\mathrm{CD} 8^{+} \mathrm{T}$ lymphocytes, natural killer (NK) cells, and dendritic cells in the intestinal lamina propria were increased together with increased colonic levels of IL-6, IL-10, IL-18, IFN- $\gamma$, TNF- $\alpha$, IL-4, IL-5, granulocyte-macrophage colony-stimulating factor (GM-CSF), and nitric oxide (NO). Intestinal angiogenesis which is an integral component of inflammatory bowel disease (IBD) pathogenesis and marks the occurrence of chronic inflammation was increased. Diets containing milk-derived components including bovine milk-derived iron-saturated lactoferrin (Fe-bLF), angiogenin, osteopontin (OPN), Modulen IBD (Nestle Healthsciences, Rhodes, Australia), colostrum whey protein (WP), and cis-9,trans-11-CLA-enriched milk fat inhibited the various disease symptoms of colitis. The CLA-enriched milk fat was particularly effective at reducing BW loss, epithelium damage, and inflammatory cytokine expression, whereas Modulen IBD was the most effective at reducing the clinical and inflammatory score. Both Fe-bLF and OPN showed promise in inhibiting inflammation. GM-CSFR = granulocyte macrophage colony stimulating factor receptor; GM-CSF Ab = granulocyte macrophage colony stimulating factor antibody; DC = dendritic cells; Ang = angiogenin. Color version available online.

colonic inflammation in a DSS-induced colitis model (Axelsson et al., 1996). Both DC and macrophages have evolved functional niches that promote cooperation in the prevention of untoward intestinal inflammation in the steady state and in the eradication of invasive microorganisms during infection (Leon et al., 2006). Therefore, considering previous studies, it can be proposed that the treatments used in the present study were successful in reducing the inflammation in mice with chronic IBD.

It has also been reported that circulating $\mathrm{CD} 4(+)$ and CD8(+) $\mathrm{T}$ cells activated in IBD are associated with plasma markers of inflammation (Funderburg et al., 2013). Therefore, cytokine analysis was performed to quantify their role in pathogenesis of the IBD. It was found that plasma levels of IL-6, IL-10, IL-18, IFN- $\gamma$, TNF- $\alpha$, IL-4, Il-5, GM-CSF, and NO were elevated in mice with DSS-induced colitis. The major cytokines in Crohn's disease arise from $\mathrm{T}$ helper $1 \mathrm{CD}^{+} \mathrm{T}$ cell differentiation, whereas a $\mathrm{T}$ helper 2-like differentiation process is reported to occur in UC, resulting in the expansion of natural killer $\mathrm{T}$ cells producing IL5, TNF- $\alpha$, and IL-6 (Strober and Fuss, 2011). In the present study, significant decreases in intestinal cytokine expression were observed in mice fed the dairy component-supplemented diets when compared with the DSS-administered mice fed the control base diet, in accord with the significant decreases in the infiltration 
of leukocytes. The CLA-enriched milk fat was the most effective at efficiently downregulating the proinflammatory markers in mice with colitis. It was observed that Fe-bLF led to a significant downregulation of all inflammatory cytokines. The anti-inflammatory properties of Fe-bLF are well established (Samarasinghe et al., 2014; Kanwar et al., 2015). Angiogenin showed highly significant downregulation $(P \leq 0.01)$ in expression of IL-6, IL-10, IFN- $\gamma$, and TNF- $\alpha$. Angiogenin has been reported to suppress the TNF- $\alpha$-induced inflammatory response through inhibition of TANK-binding kinase 1-mediated NF- $\kappa \mathrm{B}$ nuclear translocation (Lee et al., 2014). Both colostral whey and milk whey were reported to inhibit neutrophil chemotaxis (Wong et al., 1997). Bovine colostrum whey appears to protect and preserve the integrity of the intestinal mucosal barrier by inhibiting the expression levels of early and late inflammatory genes following invasion by enteric pathogens (Blais et al., 2015). It has been previously shown that dietary cheese WP reduced DSS-induced gene expression of the inflammation markers IL-1 $\beta$, calprotectin, and inducible NO synthase, and diminished the clinical symptoms diarrhea and fecal blood loss, thereby protecting rats against DSS-induced colitis (Sprong et al., 2010). On the other hand, the normal cheese diet led to increase in inflammatory and immune regulatory responses (Hosoya et al., 2012). Thus, these findings correlated with our studies. Colostrum WP is generally recommended as safe approved by the Food and Drug Administration (http://www.fda.gov/ downloads/Drugs/GuidanceComplianceRegulatoryInformation/EnforcementActivitiesbyFDA/CyberLetters/ucm056389.pdf). Colostrum proteins are known to inhibit NF- $\kappa \mathrm{B}$-mediated proinflammatory cytokine expression and switch off markers of inflammation (López-Posadas et al., 2010).

The growth factors produced in the gut, include epidermal growth factor, TGF- $\alpha$, TGF- $\beta$, amphiregulin, betacellulin, and heparin-binding epidermal growth factor-like peptide. These factors are also present in colostrum. This may be the reason why colostrum promotes repair of the mucosal lining of the gut.

Osteopontin expression by CD103-ve dendritic cells has been reported to drive intestinal inflammation (Kourepini et al., 2014). In contrast, the results of the present study indicate that oral OPN inhibits intestinal inflammation. As mentioned, our results are in agreement with those of da Silva et al. (2009), who showed that delivery of bovine milk OPN to mice via their drinking water, $24 \mathrm{~h}$ before and during administration of DSS, ameliorated the symptoms of colitis. In Hayashida et al. (2004), TGF- 31 expression was increased, whereas the levels of the proinflammatory mediators granulite colony-stimulating factor, IFN- $\gamma$, macrophage colony-stimulating factor, $\mathrm{TNF}-\alpha$, monokine induced by IFN- $\gamma$, and RANTES were decreased in colon tissue samples. In the present study, OPN reduced the levels of all cytokines, including IL-6 whose expression correlated with disease activity in IBD patients, where it plays an important role in mediating the resistance of lamina propria $\mathrm{T}$ cells against apoptosis (Teague et al., 1997). The expression of NO, which has been associated with the initiation and maintenance of inflammation in IBD (Kolios et al., 2004), was significantly lowered in all the treatment groups. Modulen IBD and CLA also led to significant downregulation in expression of all cytokines. A phase IV clinical trial conducted in 2005 compared the efficacy of Modulen IBD to steroids (prednisolone) in inducing mucosal healing in Crohn's disease and confirmed Modulen IBD as a nutritional anti-inflammatory treatments for Crohn's disease (http://clinicaltrials.gov/show/NCT00265772; Donnellan et al., 2013). The beneficial effects of colostrum protein supplementation have been related to an increase in anti-inflammatory cytokines (Duff et al., 2013). Conjugated linoleic acid has been reported to decrease the inflammation in atherosclerosis by inhibiting proinflammatory cytokines (Lee et al., 1994). It was confirmed that CLA-milk fat was the most effective treatment in efficiently downregulating the proinflammatory markers in mice with chronic IBD. This was also in accordance with our previously published findings where we reported that CLA significantly reduced circulating allergen-specific $\operatorname{IgE}$ and IgG1 levels, together with reductions in bronchoalveolar lavage fluid of IL-5 and CCL11 (Kanwar et al., 2008a).

Angiogenesis is an integral component of IBD pathogenesis (Danese et al., 2006). Inflammation-dependent angiogenesis has been reported in both Crohn's disease and UC patients, as evidenced by increased microvessel density in the intestinal mucosa. In the present study it was observed that both Fe-bLF CLA-enriched milk fat and Modulen IBD exhibited antiangiogenic effects, as evidenced by significant downregulation of CD31, CD105, and DiOC7. Bovine LF has been reported to directly inhibit the angiogenic activation of endothelial cells in vitro (Yeom et al., 2011), and when orally administered it inhibited vascular endothelial growth factor-induced angiogenesis in healthy rats (Norrby et al., 2001) and tumor angiogenesis in models of cancer (Tung et al., 2013). Cis-9,trans-11 CLA significantly decreased vascular endothelial growth factor-A mRNA and protein levels in co-cultured MCF-7 cells (Wang et al., 2005), and oral cis-9,trans-11 CLA inhibited functional vascularization of a subcutaneously injected Matrigel pellet (Sigma-Aldrich) and decreased serum vascular endothelial growth factor concentrations in mice (Masso-Welch et al., 2004). The effects of TGF- $\beta$, 
the active component of Modulen IBD, on angiogenesis are controversial and context-dependent. Transforming growth factor- $\beta$ is reported to promote the proliferation and migration of endothelial cells at low concentrations, whereas high concentrations have the opposite effect (Pepper, 1997). Osteopontin led to a significant inhibition of CD105 alone; it is well known to be proangiogenic (Chakraborty et al., 2006), and thus oral OPN might be anti-angiogenic. Thrombin-cleaved fragments of OPN are more potent for migration of endothelial cells, raising the possibility that some fragments of OPN formed after digestion may do the opposite and act as dominant-negative inhibitors, thereby blocking angiogenesis. Of relevance, a C-terminal domain fragment of OPN suppresses arginine-glycine-aspartic acid-dependent cell adhesion of the thrombin fragment, and may thereby suppress OPN functions (Takahashi et al., 1998). Cancer-related studies have shown that angiogenin is expressed in colorectal cancer, where it is significantly correlated with microvessel counts and infiltration of macrophages (Etoh et al., 2000). Other studies have reported that angiogenin is elevated in the serum of patients with IBD, suggesting it might mediate angiogenesis and vascular permeability in the mucosa of patients with IBD (Koutroubakis et al., 2004). In contrast, orally delivered angiogenin had no detectable effect on intestinal angiogenesis.

Mice fed Fe-bLF and Modulen IBD diets showed highly significant increase in apoptotic index of CD3+ cells, whereas angiogenin, colostrum WP, and CLA milk fat also led to a significant increase. This may be the reason of similar MPO activity in both Modulen IBD and Fe-bLF-fed mice. A previously published study has shown that a decrease in the number of CD3+ cells leads to lowering in expression of TNF- $\alpha$ and, hence, leads to downregulation of inflammatory response in IBD (Carol et al., 2006).

\section{CONCLUSIONS}

This is the first report to compare the effects of key milk components (FE-bLF, angiogenin, OPN, Modulen IBD, colostrum WP, and CLA-milk fat) in IBD. The results revealed that each of the dairy supplements attenuated the severity of DSS-induced colitis in mice and displayed differing effectiveness against specific disease parameters. The CLA-enriched milk fat was the best at restoring $\mathrm{BW}$, inhibiting proinflammatory cytokine expression, and improving the epithelium damage score, whereas Modulen IBD was the most effective at reducing the clinical and inflammatory scores. It will be fascinating to determine which of the dietary supplements work in synergy to combat IBD.

\section{ACKNOWLEDGMENTS}

The authors have no relevant affiliations or financial involvement with any organization or entity with a financial interest in or financial conflict with the subject matter or materials discussed in the manuscript.

\section{REFERENCES}

Artym, J. 2009. [The role of lactoferrin in the iron metabolism. Part II. Antimicrobial and antiinflammatory effect of lactoferrin by chelation of iron]. Postepy Hig. Med. Dosw. 64:604-616. [In Polish]

Atai, N. A., M. Bansal, C. Lo, J. Bosman, W. Tigchelaar, K. S. Bosch, A. Jonker, P. C. De Witt Hamer, D. Troost, and C. A. Mcculloch. 2011. Osteopontin is up-regulated and associated with neutrophil and macrophage infiltration in glioblastoma. Immunology 132:39-48.

Axelsson, L.-G., E. Landström, T. Goldschmidt, A. Grönberg, and A.C. Bylund-Fellenius. 1996. Dextran sulfate sodium (DSS) induced experimental colitis in immunodeficient mice: Effects in CD4+-cell depleted, athymic and NK-cell depleted SCID mice. Inflamm. Res. 45:181-191.

Bicknell, R., and B. L. Vallee. 1988. Angiogenin activates endothelial cell phospholipase C. Proc. Natl. Acad. Sci. USA 85:5961-5965.

Blais, M., M. Fortier, Y. Pouliot, S. Gauthier, Y. Boutin, C. Asselin, and M. Lessard. 2015. Colostrum whey down-regulates the expression of early and late inflammatory response genes induced by Escherichia coli and Salmonella enterica Typhimurium components in intestinal epithelial cells. Br. J. Nutr. 113:200-211.

Borrelli, O., L. Cordischi, M. Cirulli, M. Paganelli, V. Labalestra, S. Uccini, P. M. Russo, and S. Cucchiara. 2006. Polymeric diet alone versus corticosteroids in the treatment of active pediatric Crohn's disease: A randomized controlled open-label trial. Clin. Gastroenterol. Hepatol. 4:744-753.

Buchanan, E., W. Gaunt, T. Cardigan, V. Garrick, P. Mcgrogan, and R. Russell. 2009. The use of exclusive enteral nutrition for induction of remission in children with Crohn's disease demonstrates that disease phenotype does not influence clinical remission. Aliment. Pharmacol. Ther. 30:501-507.

Butler, W. T. 1989. The nature and significance of osteopontin. Connect. Tissue Res. 23:123-136.

Carol, M., N. Borruel, M. Antolin, M. Llopis, F. Casellas, F. Guarner, and J.-R. Malagelada. 2006. Modulation of apoptosis in intestinal lymphocytes by a probiotic bacteria in Crohn's disease. J. Leukoc. Biol. 79:917-922.

Chakraborty, G., S. Jain, R. Behera, M. Ahmed, P. Sharma, V. Kumar, and G. C. Kundu. 2006. The multifaceted roles of osteopontin in cell signaling, tumor progression and angiogenesis. Curr. Mol. Med. 6:819-830.

Changhua, L., Y. Jindong, L. Defa, Z. Lidan, Q. Shiyan, and X. Jianjun. 2005. Conjugated linoleic acid attenuates the production and gene expression of proinflammatory cytokines in weaned pigs challenged with lipopolysaccharide. J. Nutr. 135:239-244.

Chin, S. F., J. M. Storkson, K. J. Albright, M. E. Cook, and M. W. Pariza. 1994. Conjugated linoleic acid is a growth factor for rats as shown by enhanced weight gain and improved feed efficiency. J. Nutr. 124:2344-2349.

Conneely, O. M. 2001. Antiinflammatory activities of lactoferrin. J. Am. Coll. Nutr. 20:389S-395S.

da Silva, A. P. B., R. P. Ellen, E. S. Sørensen, H. A. Goldberg, R. Zohar, and J. Sodek. 2009. Osteopontin attenuation of dextran sulfate sodium-induced colitis in mice. Lab. Invest. 89:1169-1181.

Da Silva, A. P. B., A. Pollett, S. R. Rittling, D. T. Denhardt, J. Sodek, and R. Zohar. 2006. Exacerbated tissue destruction in DSSinduced acute colitis of OPN-null mice is associated with downregulation of TNF- $\alpha$ expression and non-programmed cell death. J. Cell. Physiol. 208:629-639. 
Danese, S., M. Sans, C. De La Motte, C. Graziani, G. West, M. H. Phillips, R. Pola, S. Rutella, J. Willis, and A. Gasbarrini. 2006. Angiogenesis as a novel component of inflammatory bowel disease pathogenesis. Gastroenterology 130:2060-2073.

De Vos, M., V. Huygelen, G. Van Raemdonck, S. Willemen, E. Fransen, X. Van Ostade, C. Casteleyn, S. Van Cruchten, and C. Van Ginneken. 2014. Supplementing formula-fed piglets with a low molecular weight fraction of bovine colostrum whey results in an improved intestinal barrier. J. Anim. Sci. 92:3491-3501.

Donnellan, C. F., L. H. Yann, and S. Lal. 2013. Nutritional management of Crohn's disease. Therap. Adv. Gastroenterol. 6:231-242.

Dowling, J. K., C. E. Mccoy, S. L. Doyle, N. Benlarbi, M. Canavan, L. A. O'Neill, and C. E. Loscher. 2013. Conjugated linoleic acid suppresses IRF3 activation via modulation of CD14. J. Nutr. Biochem. 24:920-928.

Draper, E., J. Decourcey, S. C. Higgins, M. Canavan, F. Mcevoy, M. Lynch, B. Keogh, C. Reynolds, H. M. Roche, and K. H. Mills. 2014. Conjugated linoleic acid suppresses dendritic cell activation and subsequent Th17 responses. J. Nutr. Biochem. 25:741-749.

Duff, W. R., P. Chilibeck, J. Rooke, M. Kaviani, J. Krentz, and D. Haines. 2014. The effect of bovine colostrum supplementation in older adults during resistance training. Int. J. Sport Nutr. Exerc. Metab. 24:276-285 PubMed

EFSA. 2012. EFSA panel on dietetic products, nutrition and allergies (NDA). EFSA Journal 10:2701. http://dx.doi.org/10.2903/J. EFSA.2012.2701.

Ek, W. E., M. D'Amato, and J. Halfvarson. 2014. The history of genetics in inflammatory bowel disease. Ann. Gastroenterol. 27:294303.

Etoh, T., K. Shibuta, G. F. Barnard, S. Kitano, and M. Mori. 2000. Angiogenin expression in human colorectal cancer: The role of focal macrophage infiltration. Clin. Cancer Res. 6:3545-3551.

Fell, J. M., M. Paintin, F. Arnaud-Battandier, R. Beattie, A. Hollis, P. Kitching, A. Donnet-Hughes, T. Macdonald, and J. Walker-Smith. 2000. Mucosal healing and a fall in mucosal pro-inflammatory cytokine mRNA induced by a specific oral polymeric diet in paediatric Crohn's disease. Aliment. Pharmacol. Ther. 14:281-289.

Fell, J. M. 2005. Control of systemic and local inflammation with transforming growth factor $\beta$ containing formulas. J. Parenter. Enter. Nutr. 29:S126-S128.

Funderburg, N. T., S. R. Stubblefield Park, H. C. Sung, G. Hardy, B. Clagett, J. Ignatz-Hoover, C. V. Harding, P. Fu, J. A. Katz, M M. Lederman, and A. D. Levine. 2013. Circulating CD4(+) and CD8(+) T cells are activated in inflammatory bowel disease and are associated with plasma markers of inflammation. Immunology 140:87-97.

Gao, X., and Z. Xu. 2008. Mechanisms of action of angiogenin. Acta Biochim. Biophys. Sin. (Shanghai) 40:619-624.

Gentile, P., and H. E. Broxmeyer. 1983. Suppression of mouse myelopoiesis by administration of human lactoferrin in vivo and the comparative action of human transferrin. Blood 61:982-993.

Hartog, A., I. Leenders, P. M. Van Der Kraan, and J. Garssen. 2007. Anti-inflammatory effects of orally ingested lactoferrin and glycine in different zymosan-induced inflammation models: Evidence for synergistic activity. Int. Immunopharmacol. 7:1784-1792.

Hayashida, K., T. Kaneko, T. Takeuchi, H. Shimizu, K. Ando, and E. Harada. 2004. Oral administration of lactoferrin inhibits inflammation and nociception in rat adjuvant-induced arthritis. J. Vet. Med. Sci. 66:149-154.

Herrera-Meza, M. S., M. Mendoza-López, O. García-Barradas, M. Sanchez-Otero, E. Silva-Hernández, J. Angulo, and R. Oliart-Ros. 2013. Dietary anhydrous milk fat naturally enriched with conjugated linoleic acid and vaccenic acid modify cardiovascular risk biomarkers in spontaneously hypertensive rats. Int. J. Food Sci. Nutr. 64:575-586.

Hosoya, T., A. Ogawa, F. Sakai, and Y. Kadooka. 2012. A cheese-containing diet modulates immune responses and alleviates dextran sodium sulfate-induced colitis in mice. J. Dairy Sci. 95:2810-2818.

Jaudszus, A., M. Krokowski, P. Möckel, Y. Darcan, A. Avagyan, P. Matricardi, G. Jahreis, and E. Hamelmann. 2008. Cis-9, trans11-conjugated linoleic acid inhibits allergic sensitization and air- way inflammation via a PPAR $\gamma$-related mechanism in mice. J Nutr. 138:1336-1342.

Kahles, F., H. M. Findeisen, and D. Bruemmer. 2014. Osteopontin: A novel regulator at the cross roads of inflammation, obesity and diabetes. Mol. Metab. 3:384-393.

Kanwar, J. R., R. K. Kanwar, X. Sun, V. Punj, H. Matta, S. M. Morley, A. Parratt, M. Puri, and R. Sehgal. 2009. Molecular and biotechnological advances in milk proteins in relation to human health. Curr. Protein Pept. Sci. 10:308-338.

Kanwar, J. R., G. Mahidhara, and R. K. Kanwar. 2012. Novel alginate-enclosed chitosan-calcium phosphate-loaded iron-saturated bovine lactoferrin nanocarriers for oral delivery in colon cancer therapy. Nanomedicine (Lond.) 7:1521-1550.

Kanwar, J. R., G. Mahidhara, K. Roy, S. Sasidharan, S. Krishnakumar, N. Prasad, R. Sehgal, and R. K. Kanwar. 2015. Fe-bLf nanoformulation targets survivin to kill colon cancer stem cells and maintains absorption of iron, calcium and zinc. Nanomedicine (Lond.) 10:35-55.

Kanwar, J. R., K. P. Palmano, X. Sun, R. K. Kanwar, R. Gupta, N. Haggarty, A. Rowan, S. Ram, and G. W. Krissansen. 2008a. 'Ironsaturated' lactoferrin is a potent natural adjuvant for augmenting cancer chemotherapy. Immunol. Cell Biol. 86:277-288.

Kanwar, R. K., A. Macgibbon, P. Black, J. Kanwar, A. Rowan, M. Vale, and G. Krissansen. 2008b. Bovine milk fat enriched in conjugated linoleic and vaccenic acids attenuates allergic airway disease in mice. Clin. Exp. Allergy 38:208-218.

Kaser, A., S. Zeissig, and R. S. Blumberg. 2010. Inflammatory bowel disease. Annu. Rev. Immunol. 28:573-621.

Ke, C., Z. Lan, L. Hua, Z. Ying, X. Humina, S. Jia, T. Weizheng, Y. Ping, C. Lingying, and M. Meng. 2015. Iron metabolism in infants: Influence of bovine lactoferrin from iron-fortified formula. Nutrition 31:304-309.

Kennedy, R. S., G. P. Konok, G. Bounous, S. Baruchel, and T. D. Lee. 1995. The use of a whey protein concentrate in the treatment of patients with metastatic carcinoma: A phase I-II clinical study. Anticancer Res. 15:2643-2649.

Knight, M. I., A. M. Tester, M. B. Mcdonagh, A. Brown, J. Cottrell, J. Wang, P. Hobman, and B. G. Cocks. 2014. Milk-derived ribonuclease 5 preparations induce myogenic differentiation in vitro and muscle growth in vivo. J. Dairy Sci. 97:7325-7333.

Koh, A., A. P. B. Da Silva, A. K. Bansal, M. Bansal, C. Sun, H. Lee, M. Glogauer, J. Sodek, and R. Zohar. 2007. Role of osteopontin in neutrophil function. Immunology 122:466-475.

Kolios, G., V. Valatas, and S. G. Ward. 2004. Nitric oxide in inflammatory bowel disease: A universal messenger in an unsolved puzzle. Immunology 113:427-437.

Kourepini, E., M. Aggelakopoulou, T. Alissafi, N. Paschalidis, D. C. Simoes, and V. Panoutsakopoulou. 2014. Osteopontin expression by $\mathrm{CD}_{103^{-}}$dendritic cells drives intestinal inflammation. Proc Natl. Acad. Sci. USA 111:E856-E865.

Koutroubakis, I. E., C. Xidakis, K. Karmiris, A. Sfiridaki, E. Kandidaki, and E. A. Kouroumalis. 2004. Serum angiogenin in inflammatory bowel disease. Dig. Dis. Sci. 49:1758-1762.

Krawisz, J. E., P. Sharon, and W. Stenson. 1984. Quantitative assay for acute intestinal inflammation based on myeloperoxidase activity. Gastroenterology 87:1344-1350.

Krissansen, G. W. 2007. Emerging health properties of whey proteins and their clinical implications. J. Am. Coll. Nutr. 26:713S-723S.

Lee, B., X. Yin, S. M. Griffey, and M. L. Marco. 2015. Attenuation of colitis by Lactobacillus casei BL23 is dependent on the dairy delivery matrix. Appl. Environ. Microbiol. 81:6425-6435.

Lee, K. N., D. Kritchevsky, and M. W. Parizaa. 1994. Conjugated linoleic acid and atherosclerosis in rabbits. Atherosclerosis 108:19-25.

Lee, S. H., K. W. Kim, K.-M. Min, K.-W. Kim, S.-I. Chang, and J. C. Kim. 2014. Angiogenin reduces immune inflammation via inhibition of TANK-binding kinase 1 expression in human corneal fibroblast cells. Mediators Inflamm. 2014:861435.

Leon, F., L. E. Smythies, P. D. Smith, and B. L. Kelsall. 2006. Involvement of dendritic cells in the pathogenesis of inflammatory bowel disease. Adv. Exp. Med. Biol. 579:117-132. 
Li, X.-J., D.-P. Liu, H.-L. Chen, X.-H. Pan, Q.-Y. Kong, and Q.-F. Pang. 2012. Lactoferrin protects against lipopolysaccharide-induced acute lung injury in mice. Int. Immunopharmacol. 12:460464.

Liu, S., J. Ren, Y. Zhao, G. Han, Z. Hong, D. Yan, J. Chen, G. Gu, G. Wang, and X. Wang. 2013. Nonthyroidal illness syndrome: Is it far away from Crohn's disease? J. Clin. Gastroenterol. 47:153-159.

López-Posadas, R., I. Ballester, C. Mascaraque, M. Suarez, A. Zarzuelo, O. Martínez-Augustin, and F. Sanchez De Medina. 2010. Flavonoids exert distinct modulatory actions on cyclooxygenase 2 and NF- $\mathrm{BB}$ in an intestinal epithelial cell line (IEC18). Br. J. Pharmacol. 160:1714-1726.

Loscher, C. E., E. Draper, O. Leavy, D. Kelleher, K. H. Mills, and H. M. Roche. 2005. Conjugated linoleic acid suppresses NF- $\kappa B$ activation and IL-12 production in dendritic cells through ERKmediated IL-10 induction. J. Immunol. 175:4990-4998.

MacDonald, H. B. 2000. Conjugated linoleic acid and disease prevention: a review of current knowledge. J. Am. Coll. Nutr. 19:111S$118 \mathrm{~S}$.

Masso-Welch, P. A., D. Zangani, C. Ip, M. M. Vaughan, S. F. Shoemaker, S. O. Mcgee, and M. M. Ip. 2004. Isomers of conjugated linoleic acid differ in their effects on angiogenesis and survival of mouse mammary adipose vasculature. J. Nutr. 134:299-307.

Mayberry, J. C. G. 2004. Gastroenterology Update: Evidence-Based Reviews for Continuing Professional Development. Radcliffe Publishing Ltd., Milton Keynes, UK.

Meller, R., S. L. Stevens, M. Minami, J. A. Cameron, S. King, H. Rosenzweig, K. Doyle, N. S. Lessov, R. P. Simon, and M. P. Stenzel-Poore. 2005. Neuroprotection by osteopontin in stroke. J. Cereb. Blood Flow Metab. 25:217-225

Nemet, K., and I. Simonovits. 1985. The biological role of lactoferrin. Haematologia (Budap.) 18:3-12.

Norrby, K., I. Mattsby-Baltzer, M. Innocenti, and S. Tuneberg. 2001. Orally administered bovine lactoferrin systemically inhibits VEGF165-mediated angiogenesis in the rat. Int. J. Cancer 91:236240.

O'Shea, M., J. Bassaganya-Riera, and I. C. Mohede. 2004. Immunomodulatory properties of conjugated linoleic acid. Am. J. Clin. Nutr. 79:1199S-1206S

Okayasu, I., S. Hatakeyama, M. Yamada, T. Ohkusa, Y. Inagaki, and R. Nakaya. 1990. A novel method in the induction of reliable experimental acute and chronic ulcerative colitis in mice. Gastroenterology 98:694-702.

Ono, T., S. Morishita, and M. Murakoshi. 2013. Novel function of bovine lactoferrin in lipid metabolism: Visceral fat reduction by enteric-coated lactoferrin. PharmaNutrition 1:32-34.

Penedo, L. A., J. C. Nunes, M. A. S. Gama, P. E. C. Leite, T. F. Quirico-Santos, and A. G. Torres. 2013. Intake of butter naturally enriched with cis9, trans11 conjugated linoleic acid reduces systemic inflammatory mediators in healthy young adults. J. Nutr. Biochem. 24:2144-2151.

Pepper, M. S. 1997. Transforming growth factor-beta: Vasculogenesis, angiogenesis, and vessel wall integrity. Cytokine Growth Factor Rev. 8:21-43.

Podolsky, D. K. 1991. Inflammatory bowel disease. N. Engl. J. Med. 325:928-937.

Rittling, S. R., P. Wejse, K. Yagiz, G. Warot, and T. Hui. 2014. Suppression of tumour growth by orally administered osteopontin is accompanied by alterations in tumour blood vessels. Br. J. Cancer 110:1269-1277.

Sagwal, R., and V. Kansal. 2010. Synergistic effect of synthetic conjugated linoleic acid \& non fat milk on fat deposition \& lipid metabolism in mice. Indian J. Med. Res. 131:449-454.

Samarasinghe, R. M., R. K. Kanwar, and J. R. Kanwar. 2014. The effect of oral administration of iron saturated-bovine lactoferrin encapsulated chitosan-nanocarriers on osteoarthritis. Biomaterials 35:7522-7534

Sands, B. E. 2004. From symptom to diagnosis: Clinical distinctions among various forms of intestinal inflammation. Gastroenterology 126:1518-1532.

Sartor, R. B. 1995. Current concepts of the etiology and pathogenesis of ulcerative colitis and Crohn's disease. Gastroenterol. Clin. North Am. 24:475-507.

Sébédio, J.-L., S. Gnaedig, and J.-M. Chardigny. 1999. Recent advances in conjugated linoleic acid research. Curr. Opin. Clin. Nutr. Metab. Care 2:499-506.

Shi, Z., B. Wang, T. Chihanga, M. A. Kennedy, and G. F. Weber. 2014. Energy metabolism during anchorage-independence. Induction by osteopontin-c. PLoS One 9:e105675.

Sprong, R. C., A. Schonewille, and R. Van Der Meer. 2010. Dietary cheese whey protein protects rats against mild dextran sulfate sodium-induced colitis: Role of mucin and microbiota. J. Dairy Sci. 93:1364-1371.

Strober, W., and I. J. Fuss. 2011. Proinflammatory cytokines in the pathogenesis of inflammatory bowel diseases. Gastroenterology 140:1756-1767.

Sun, X., J. Zhang, A. Macgibbon, P. Black, and G. Krissansen. 2011. Bovine milk fat enriched in conjugated linoleic and vaccenic acids attenuates allergic dermatitis in mice. Clin. Exp. Allergy 41:729738

Takahashi, K., F. Takahashi, K. K. Tanabe, H. Takahashi, and Y. Fukuchi. 1998. The carboxyl- terminal fragment of osteopontin suppresses arginine-glycine-asparatic acid-dependent cell adhesion. Biochem. Mol. Biol. Int. 46:1081-1092.

Teague, T. K., P. Marrack, J. W. Kappler, and A. T. Vella. 1997. IL-6 rescues resting mouse $\mathrm{T}$ cells from apoptosis. J. Immunol. 158:5791-5796.

ten Hove, T., C. Van Montfrans, M. Peppelenbosch, and S. Van Deventer. 2002. Infliximab treatment induces apoptosis of lamina propria T lymphocytes in Crohn's disease. Gut 50:206-211.

Triantafillidis, J., A. Stamataki, A. Gikas, and G. Malgarinos. 2010. Maintenance treatment of Crohn's disease with a polymeric feed rich in TGF-3. Ann. Gastroenterol. 23:113-118.

Triantafillidis, J. K., E. Merikas, and F. Georgopoulos. 2011. Current and emerging drugs for the treatment of inflammatory bowel disease. Drug Des. Devel. Ther. 5:185-210.

Tung, Y.-T., H.-L. Chen, C.-C. Yen, P.-Y. Lee, H.-C. Tsai, M.-F. Lin, and C.-M. Chen. 2013. Bovine lactoferrin inhibits lung cancer growth through suppression of both inflammation and expression of vascular endothelial growth factor. J. Dairy Sci. 96:2095-2106.

Uede, T. 2011. Osteopontin, intrinsic tissue regulator of intractable inflammatory diseases. Pathol. Int. 61:265-280.

Van Barneveld, R., and F. Dunshea. 2011. Colostrum protein isolate increases gut and whole body growth and plasma IGF-I in neonatal pigs. Asian-Australas. J. Anim. Sci. 24:670-677.

Wang, L.-S., Y.-W. Huang, Y. Sugimoto, S. Liu, H.-L. Chang, W. Ye, S. Shu, and Y. C. Lin. 2005. Effects of human breast stromal cells on conjugated linoleic acid (CLA) modulated vascular endothelial growth factor-A (VEGF-A) expression in MCF-7 cells. Anticancer Res. 25:4061-4068

Wong, C. W., A. H. Liu, G. O. Regester, G. L. Francis, and D. L. Watson. 1997. Influence of whey and purified whey proteins on neutrophil functions in sheep. J. Dairy Res. 64:281-288.

Yeom, M., J. Park, B. Lee, S.-Y. Choi, K. S. Kim, H. Lee, and D.H. Hahm. 2011. Lactoferrin inhibits the inflammatory and angiogenic activation of bovine aortic endothelial cells. Inflamm. Res. 60:475-482. 